\title{
Racial differences between African-American and white women in insulin resistance and visceral adiposity are associated with differences in apoCIII containing apoAI and apoB lipoproteins
}

Liyun Wang ${ }^{1}$, Frank M Sacks ${ }^{1,2^{*}}$, Jeremy D Furtado ${ }^{1}$, Madia Ricks ${ }^{3}$, Amber B Courville ${ }^{4}$ and Anne E Sumner ${ }^{3}$

\begin{abstract}
Background: African-Americans have higher HDL, less visceral adipose tissue (VAT) and lower triglyceride (TG) and apoCIII concentrations than whites, despite being more insulin-resistant. We studied in African-American and white women the influences of insulin resistance and VAT on the apoAl concentrations of two HDL subspecies, one that contains apoClll that is associated with increased risk of coronary heart disease (CHD) and one that does not have apoCIII that is associated with decreased CHD; and on the apoCIII concentrations of HDL and of the apoB lipoproteins.

Methods: The participants were 32 women (14 African-Americans, 18 white) of similar age (39 \pm 12 vs. $42 \pm 11 \mathrm{y}$ ). Mean BMI was $34 \mathrm{~kg} / \mathrm{m}^{2}$ in the African-Americans compared to 30 in the whites. A standard diet (33\% fat, 52\% carbohydrate, 15\% protein) was provided for 7 days followed by a test meal (40\% fat, 40\% carbohydrate, 20\% protein) on Day 8. Insulin sensitivity index $\left(S_{1}\right)$ was calculated from the minimal model.

Results: After controlling for $\mathrm{S}_{1}$, African-Americans have a higher mean apoAl level in HDL with apoCIII compared with whites $(12.9 \pm 2.8$ and $10.9 \pm 2.9 \mathrm{mg} / \mathrm{dL}$, respectively, $P=0.05)$. S was associated with higher apoAl in HDL with apoCIII, whereas VAT was not associated with this HDL subspecies. This pattern of results was reversed for apoCIII concentrations in apoB lipoproteins. After adjusting for $\mathrm{S}_{1}$, African-Americans had lower apoClll in apoB lipoproteins. $\mathrm{S}_{1}$ was associated with lower apoCIII in total apoB lipoproteins, whereas VAT was associated with higher apoCIII in all the apoB lipoproteins. Additional adjustment for VAT tended to reduce the difference in apoCIII between the groups.

Conclusions: African-American women have a higher HDL with apoCIII level than whites when controlled for insulin sensitivity. African-Americans have lower insulin sensitivity. Insulin sensitivity is associated with higher levels of HDL with apoCIII. ApoCIII levels in VLDL are lower in African-American women than whites, also affected by insulin sensitivity which is associated with low apoCIII in VLDL. VAT has a strong association with apoCIII in apoB lipoproteins but not with apoAl in HDL with apoCIII.
\end{abstract}

Trial registration: ClinicalTrials.gov Identifier: NCT00484861

Keywords: ApoAl, ApoCIII, HDL, ApoB lipoproteins, Visceral adipose tissue, Insulin resistance, African-Americans, Coronary heart disease

\footnotetext{
*Correspondence: fsacks@hsph.harvard.edu

'Department of Nutrition, Harvard School of Public Health, 665 Huntington

Avenue, Building 1, Room 201, Boston, MA 02115, USA

${ }^{2}$ Channing Division of Network Medicine, Department of Medicine, Brigham

and Women's Hospital and Harvard Medical School, Boston, MA, USA

Full list of author information is available at the end of the article
} 


\section{Background}

According to the US National Health and Nutrition Examination Survey (NHANES III), African-Americans have higher prevalence of cardiovascular disease compared with whites [1,2]. However, the metabolic basis for this is unknown. Paradoxically, African-Americans have less dyslipidemia compared to whites; HDL-cholesterol (HDL-C) is higher and triglycerides (TG) is lower [3-5]. Other factors complicating our understanding of the causes of CHD in African-Americans are insulin resistance, which is higher, and visceral adipose tissue (VAT) which is lower in African-Americans than whites $[4,6,7]$. Insulin resistance is a predictor of CHD risk and it is correlated with dyslipidemia [8]. If insulin resistance is a causal factor in dyslipidemia, then African-Americans would be expected to have more dyslipidemia than whites; however the opposite is true. Visceral adipose tissue (VAT) is correlated with dyslipidemia, and the lower mass of VAT in African-Americans is consistent with less dyslipidemia. However, VAT is generally correlated with insulin resistance in African-American and white populations $[9,10]$. Thus, it is unknown why TG and VAT are not usually elevated in insulin-resistant AfricanAmerican women. It is possible that the usual grouping of risk factors and metabolic influences, dyslipidemia, insulin resistance, and visceral fat, recognized in the concept of the metabolic syndrome and strong predictors of CHD, may not apply as well to African-Americans as whites. A clinical implication of this paradox is that CHD screening panels that involve HDL-c and TG may not detect risk as well in African-Americans [11-13]. That could be true if the favorable HDL and TG levels in African-Americans mask unfavorable lipoprotein subspecies and apolipoproteins that are related to high $\mathrm{CHD}$ risk.

ApoCIII is an important predictor of CHD risk [14,15]. In the circulation, apoCIII is associated with apoB lipoproteins and enhances the atherogenicity of very low density lipoproteins (VLDL) and low density lipoproteins (LDL) $[14,16]$. Evidence is accumulating that apoCIII concentrations of apoB containing lipoproteins are strong predictors of CHD [14,16-18]. ApoCIII concentration in VLDL + LDL is a more specific predictor of CHD risk than plasma TG [16]. Furthermore, we recently reported, after dividing apoB containing lipoproteins to VLDL and LDL subfractions, apoCIII levels in VLDL and LDL were each associated with CHD [14]. Several studies show that African-Americans have lower apoCIII level than whites $[19,20]$, and we previously reported that the low apoCIII level contributes to the low TG concentrations in AfricanAmericans [21].

HDL-C subtypes based on content of apoCIII are differentially associated with risk of CHD. HDL without apoCIII, the major HDL type, is inversely associated with CHD. However, a minor subclass, accounting for around
$13 \%$ of HDL cholesterol, carries apoCIII, and is linked to a higher risk of CHD. Participants with plasma HDL apoCIII concentrations in the highest compared to the lowest $20 \%$ of the population had a $60 \%$ increased risk of CHD [15]. Although African-Americans have higher HDL-C and apoAI levels than whites [3,19], it is unknown if HDL with apoCIII or HDL without apoCIII is different by race.

Most studies of lipids and cardiovascular risk have used fasting concentrations. However, recent studies have suggested that the postprandial TG level is a better predictor than the fasting TG level for assessing present and future CVD events in the nondiabetic population $[22,23]$. There is little known about postprandial lipids and apolipoproteins in African-Americans compared to whites.

Previously we reported the determinants of triglyceride levels in the participants in this research study [21]. We found that low concentrations of apoCIII and VAT contributed to the low triglyceride concentrations in AfricanAmericans. In the present study, we extended this approach to explore race differences in potentially dysfunctional HDL subspecies that we newly identified [15]. In addition, increasing understanding of apoCIII as a potentially causal risk factor [24], in its own right, led us to explore determinants of apoCIII concentrations in HDL and apoB lipoproteins. We focused on the postprandial period, hypothesizing that the postprandial lipoproteins can give us more information on race differences in HDL subspecies and apoCIII contents of HDL and apoB lipoproteins. We assessed insulin sensitivity by a frequently sampled intravenous glucose tolerance test because we anticipated that insulin sensitivity could affect the apoC-III containing lipoproteins $[25,26]$. Our goal was first to determine whether postprandial apoAI in HDL with or without apoCIII and apoCIII in apoB lipoproteins differ between African-Americans and whites, and second to determine if differences in insulin resistance or VAT influence the racial differences between groups in the lipoprotein subspecies. Indeed we found that lower insulin sensitivity in African-Americans compared to whites obscured differences in apoCIII containing lipoproteins between the racial groups.

\section{Methods}

\section{Subjects}

Nondiabetic African-American and white women of similar age and BMI were enrolled to minimize the confounding effects of age and obesity. Recruitment was by flyers, newspaper advertisements and website. Exclusion criteria were use of medications, vitamins or food supplements which affect either glucose or lipid metabolism; anemia, liver, kidney or thyroid dysfunction. The final study group had 32 non-diabetic women (14 African-Americans and 
18 whites). Age and BMI range are 22 to 59 years and 20.6 to $45.9 \mathrm{~kg} / \mathrm{m}^{2}$, respectively. Most of the subjects were part of a previous report on determinants of triglyceride levels [21]. The study was approved by the Institutional Review Board of the National Institute of Diabetes, Digestive and Kidney Diseases. All participants gave written informed consent.

\section{Protocol}

At the screening visit, a medical history, physical examination, measurement of hematology and blood chemistry, and an EKG were performed. The methods for measuring insulin resistance and body composition and the study protocol in detail have been reported previously [21]. Briefly, at the second visit an insulin-modified frequently sampled intravenous glucose tolerance test (IM-FSIGT) was performed. After a 12 hours overnight fast each participant came to the Clinical Center at 7 AM. Intravenous catheters were placed in each antecubital vein. Dextrose $(0.3 \mathrm{~g} / \mathrm{kg})$ was administered intravenously over 1 minute. An insulin $(0.03 \mathrm{U} / \mathrm{kg})$ bolus was injected at $20 \mathrm{~min}$. Blood samples were taken at $-10,-1,0,1,2,3,4,5,6,7,8,10$, $12,14,16,19,22,23,24,25,27,30,40,50,60,70,80,90$, $100,120,150,180 \mathrm{~min}$. Glucose and insulin concentrations were entered into the minimal model and the insulin sensitivity index $\left(S_{I}\right)$ (MinMOD Millenium v.6.02) calculated. The insulin sensitivity index is a calculated measure of whole body insulin sensitivity. In the absence of diabetes, the more resistance there is to insulin's ability to promote glucose uptake, the more insulin concentrations rise. This is why both insulin concentration and glucose are built into the minimal model equations. During the conduct of the FSIGT, both glucose and insulin are collected at 32 time points. Indeed the equation for $\mathrm{S}_{\mathrm{I}}$ calculates the net rate of change of glucose over time at an insulin concentration above basal. Acute insulin response to glucose (AIRg) was determined by the area under the insulin curve between 0 and $10 \mathrm{~min}$ for the insulin concentration above basal. VAT and subcutaneous adipose tissue (SAT) were measured at L2-3 using a GE Hispeed Advantage CT/I scanner (Milwaukee, WI) and analyzed on a SUN workstation (MEDx image, Sensor System, Inc., Sterling, VA). Percent body fat was determined with a dual energy X-ray absorptiometry (DXA) scan (Hologic QDR4500A, Bedford, MA).

\section{Standard diet and test meal}

The controlled diet began between 1 and 14 days after the IM-FSIGT. During the 7 day controlled dietary period, all meals were prepared in the metabolic kitchen at the NIH Clinical Center. On weekdays, participants reported in the morning to be weighed and eat breakfast. Lunch and dinner were provided in a cooler for consumption off-site. Compliance with picking up daily food packet and weekend food cooler was $100 \%$. On day 8 , the participants came to the Clinical Center at 7 AM after a 12 hour fast. The test meal was consumed. On Day 8 breakfast was provided with $30 \%$ of the energy consumed on Day 7 of the standard diet (21). The meal was an egg omelet with butter and cheddar cheese, plain bagel with cream cheese and orange juice (40\% fat, $40 \%$ carbohydrate and $20 \%$ protein). Blood samples were obtained fasting and 2, 4 and 6 hours postprandially.

\section{Standard diet}

As described previously, the Mifflin St. Jeor equation multiplied by a physical activity factor was used to estimate energy needs [21]. The physical activity factor was based on a dietician initiated interview and the National Research Council Dietary Reference Intake scale. An activity factor of $1.00-1.39$ is for sedentary activity; $1.40-1.59$ for sedentary activity plus 30-60 min of moderate activity; 1.60-1.89 for sedentary activity plus $>60 \mathrm{~min}$ of daily moderate activity; and 1.90-2.50 for sedentary activity plus $>60$ min of daily moderate activity and $>60$ min of vigorous activity or $>120 \mathrm{~min}$ of moderate activity. The macronutrient distribution of the meal was based on a typical American diet (33\% fat, 52\% carbohydrate, 15\% protein).

\section{Ultracentrifugation}

Whole plasma samples were separated into density factions by ultracentrifugation [21]. Four density fractions of plasma were collected: light VLDL $(\mathrm{d}<1.006 \mathrm{~g} / \mathrm{mL}$, Svedberg units of flotation (Sf): $60 \sim 400)$, dense VLDL $(\mathrm{d}<1.006 \mathrm{~g} / \mathrm{mL}$, Sf: $20 \sim 60)$, IDL $(1.006 \mathrm{~g} / \mathrm{mL}<\mathrm{d}<1.025 \mathrm{~g} / \mathrm{mL}), \quad \mathrm{LDL}$ $(1.025 \mathrm{~g} / \mathrm{mL}<\mathrm{d}<1.063 \mathrm{~g} / \mathrm{mL})$ and HDL $(\mathrm{d}>1.063 \mathrm{~g} / \mathrm{ml})$.

\section{ApoCIII measurement}

Sandwich ELISA procedures using affinity-purified antibodies (Academy Biomedical Company Inc., Houston, TX) were performed to determine the apoCIII concentrations in whole plasma and lipoprotein fractions. All assays were completed in triplicate.

\section{ApoAl measurement}

We measured the apoAI concentration of HDL with or without apoCIII concentration by ELISA. ELISA wells were coated with polyclonal anti-apoCIII which captured plasma lipoproteins that contain apoCIII. The apoAI concentration of the unbound fraction was measured by standard sandwich ELISA using polyclonal antiapoAI for capture and detection. This step measured the apoAI concentration of HDL that does not contain apoCIII. The lipoproteins bound to the anti-apoCIII plate were dissociated with Tween-20, and the apoAI concentration was measured by the same sandwich ELISA. This step 
measured the apoAI concentration of HDL that contains apoCIII. All assays were completed in triplicate.

\section{Statistical analyses}

Differences in demographic and metabolic characteristics between African-Americans and whites were determined with two-tailed unpaired $\mathrm{t}$-test. $P$-values $\leq 0.05$ were considered significant. Generalized least squares random effects models (REM) were used to examine race differences in the lipid response to the meal using measurements from samples collected both fasting and 2, 4 and 6 hours postprandially. All models included race and time as categorical variables. Because $S_{I}$ and VAT differ between African-Americans and whites, and they also affect lipoprotein metabolism, we performed a series of multiple variable models to gain understanding of how $\mathrm{S}_{\mathrm{I}}$ and VAT may influence the racial differences in apoCIII containing lipoproteins. Models were built by adding $\mathrm{S}_{\mathrm{I}}$ and VAT singly and together, and their effect on the coefficient for race examined. Analyses were performed with STATA, v12.0 (College Station, Texas).

\section{Results}

\section{Demographic and metabolic characteristics of the participants}

Briefly, thirty-two non-diabetic women (14 AfricanAmerican and 18 whites) were enrolled. Age and BMI ranges were 22 to 59 years and 20.6 to $45.9 \mathrm{~kg} / \mathrm{m}^{2}$, respectively. By design, the women were similar in age (Table 1). Mean BMI was $34.3 \mathrm{~kg} / \mathrm{m}^{2}$ in the African Americans compared to $30.1 \mathrm{~kg} / \mathrm{m}^{2}$ in the whites $(P=0.06)$. The two groups had similar percent body fat and waist

Table 1 Demographic and metabolic characteristics in participants $^{1}$

\begin{tabular}{|c|c|c|c|}
\hline Variable & $\begin{array}{l}\text { African-Americans } \\
\qquad(\mathrm{n}=14)\end{array}$ & $\begin{array}{l}\text { Whites } \\
(n=18)\end{array}$ & $P$-Value ${ }^{2}$ \\
\hline Age $(y)$ & $39 \pm 12$ & $42 \pm 11$ & 0.45 \\
\hline BMI & $34.3 \pm 7.4$ & $30.1 \pm 4.9$ & 0.06 \\
\hline Percent body fat (\%) & $39.7 \pm 9.1$ & $38.8 \pm 7.8$ & 0.8 \\
\hline Waist circumference (cm) & $101.0 \pm 17$ & $100.6 \pm 15$ & 0.95 \\
\hline Thigh circumference (cm) & $66 \pm 11$ & $57 \pm 7$ & 0.01 \\
\hline $\operatorname{VAT}\left(\mathrm{cm}^{2}\right)^{3}$ & $109 \pm 74$ & $114 \pm 66$ & 0.03 \\
\hline $\operatorname{SAT}\left(\mathrm{cm}^{2}\right)^{3}$ & $341 \pm 187$ & $271 \pm 139$ & 0.37 \\
\hline $\mathrm{S}_{\mathrm{I}}\left(\mathrm{mU} / \mathrm{L}^{-1} \cdot \mathrm{min}^{-1}\right)$ & $3.0 \pm 1.5$ & $5.3 \pm 2.5$ & 0.01 \\
\hline AIRg (mU. $\left.I^{-1} . \min \right)$ & $760 \pm 437$ & $215 \pm 176$ & $<0.001$ \\
\hline Family history of diabetes & $43 \%(6 / 14)$ & $44 \%(8 / 18)$ & 0.93 \\
\hline No college degree & $43 \%(6 / 14)$ & $6 \%(1 / 18)$ & 0.01 \\
\hline Graduate school & $36 \%(5 / 14)$ & $56 \%(10 / 18)$ & 0.28 \\
\hline Smokers & $2 / 14$ & $5 / 18$ & 0.38 \\
\hline
\end{tabular}

${ }^{1}$ Data presented as mean \pm SD.

${ }^{2}$ Comparisons by unpaired t-tests.

${ }^{3} P$-value adjusted for BMI with regression analysis. circumference. However, thigh circumference tended to be higher in the African-Americans $(P=0.01)$. The AfricanAmerican women had less VAT than the whites $(P=0.03)$. Subcutaneous abdominal adipose tissue did not differ by race $(P=0.37)$. The African-Americans were more insulin-resistant (lower $\mathrm{S}_{\mathrm{I}}, P=0.01$ ) and hyperinsulinemic (higher AIRg, $P<0.001$ ) than whites.

\section{Fasting lipids and apolipoproteins}

Fasting lipids and apolipoproteins did not differ significantly by race (Table 2 ).

\section{ApoAl concentration in HDL subfractions during the test meal}

The apoAI concentrations of HDL with or without apoCIII from baseline through 6 hours during the test meal were not significantly different by race (Figure 1 , left panels). However, after controlling for $S_{\mathrm{I}}$, AfricanAmerican women had significantly higher apoAI level in HDL with apoCIII than whites (mean \pm SD: $12.9 \pm 2.8$ and $10.9 \pm 2.9 \mathrm{mg} / \mathrm{dL}$, respectively, $P=0.05$ ) (Figure $1 \mathrm{~A}$, right panel). The difference between the groups in apoAI in HDL with apoCIII increased over the 6-hour postprandial study. African-American women also tended to have higher apoAI level in HDL without apoCIII than whites (Figure 1B, right panel).

\section{Determinants of apoAl concentration in each HDL subfraction}

Because $S_{I}$ and VAT were significantly lower in the African-American group, the effects of $\mathrm{S}_{\mathrm{I}}$ and VAT on the difference by race in the HDL subfractions were studied in

Table 2 Fasting lipids and apolipoproteins ${ }^{1}$

\begin{tabular}{|c|c|c|c|}
\hline Variable & $\begin{array}{l}\text { African-Americans } \\
\qquad(\mathrm{n}=14)\end{array}$ & $\begin{array}{l}\text { Whites } \\
(n=18)\end{array}$ & $P$-Value ${ }^{2}$ \\
\hline Cholesterol (mg/dL) & $185 \pm 41$ & $172 \pm 35$ & 0.20 \\
\hline $\mathrm{TG}(\mathrm{mg} / \mathrm{dL})$ & $79 \pm 45$ & $98 \pm 50$ & 0.15 \\
\hline HDL cholestrol (mg/dL) & $56 \pm 14$ & $49 \pm 11$ & 0.10 \\
\hline LDL cholesterol (mg/dL) & $113 \pm 34$ & $102 \pm 29$ & 0.23 \\
\hline ApoAl (mg/dL) & $175 \pm 32$ & $167 \pm 30$ & 0.52 \\
\hline $\begin{array}{l}\text { Apo Al of HDL with } \\
\text { ApoC-III }(\mathrm{mg} / \mathrm{dL})\end{array}$ & $13.2 \pm 3.0$ & $12.7 \pm 2.6$ & 0.57 \\
\hline $\begin{array}{l}\text { Apo Al of HDL without } \\
\text { ApoC-III (mg/dL) }\end{array}$ & $162 \pm 30$ & $154 \pm 28$ & 0.52 \\
\hline ApoCIII (mg/dL) & $10.4 \pm 3.7$ & $9.6 \pm 3.9$ & 0.55 \\
\hline HDL-ApoCIII (mg/dL) & $7.0 \pm 2.9$ & $5.7 \pm 3.1$ & 0.23 \\
\hline Light VLDL-ApoCIII (mg/dL) & $1.5 \pm 1.4$ & $1.7 \pm 1.1$ & 0.60 \\
\hline Dense VLDL-ApoCIII (mg/dL) & $0.61 \pm 0.55$ & $0.93 \pm 0.51$ & 0.10 \\
\hline IDL-ApoCIII (mg/dL) & $0.28 \pm 0.29$ & $0.32 \pm 0.28$ & 0.68 \\
\hline LDL-ApoCIII (mg/dL) & $1.0 \pm 0.6$ & $1.0 \pm 0.5$ & 0.68 \\
\hline
\end{tabular}




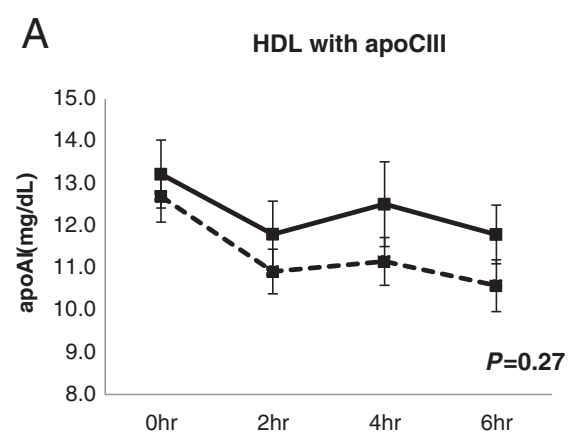

B

HDL without apoCIII

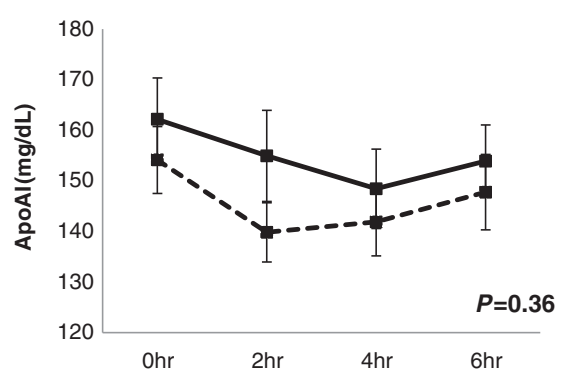

HDL with apoCIII adjusted for $S_{1}$

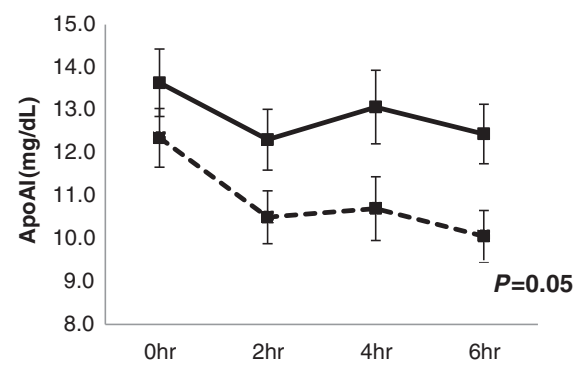

HDL without apoCIII adjusted for $S_{1}$

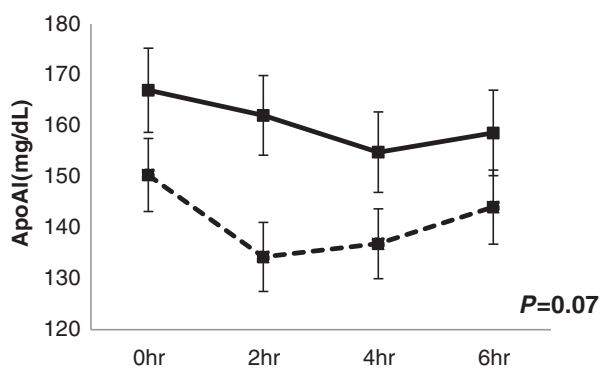

Figure $1 \mathrm{ApoAI}$ concentrations of $\mathrm{HDL}$ with or without apoCIII at baseline, 2, 4 and 6 hours postprandially. The rows present the apoAl concentration in HDL with apoCIII (A) and HDL without apoCIII (B). Panels present unadjusted (left panel) and adjusted for $\mathrm{S}_{\mathrm{I}}$ (right panel). Data is from random effect multiple models constructed to determine the effect of race on the apoAl concentration in each HDL subfraction. The $P$-value for the effect of race is presented in each diagram. African-American women: solid lines; white women: dashed lines.

multivariable models. The apoAI concentration of HDL with apoCIII was significantly directly associated with $\mathrm{S}_{\mathrm{I}}$. The regression coefficient on HDL with apoCIII of race doubled after adjustment for $\mathrm{S}_{\mathrm{I}}$ (Table 3, Model A: $\beta$-coef $=1.00$, Model B: $\beta$-coef $=1.96$ ). African-American women also tended to have higher apoAI level in HDL without apoCIII after controlling for $\mathrm{S}_{\mathrm{I}}$; which itself was associated with HDL without apoCIII (Table 3, Model B).
VAT was not significantly related to HDL with apoCIII or HDL without apoCIII (Table 3, Model C). When race, $\mathrm{S}_{\mathrm{I}}$ and VAT were included as independent variables (Table 3 Model D), apoAI level in HDL with apoCIII in AfricanAmerican women was significantly higher than in whites. Both race and $S_{I}$ were significant determinants of apoAI concentration in HDL with apoCIII; overall $R^{2}=14 \%$ (both $P=0.04$ ). In this combined model, none of these

Table 3 Random effects model to determine influence of race ${ }^{1}, S_{I}$ and VAT on apoA-I level

\begin{tabular}{|c|c|c|c|c|c|c|c|c|}
\hline \multicolumn{5}{|c|}{ ApoAl of HDL with apoCIII } & \multicolumn{4}{|c|}{ ApoAl of HDL without apoCIII } \\
\hline Model & Variables & $\beta$-coef & SE & $P$-val & Variables & $\beta$-coef & SE & $P$-val \\
\hline \multirow[t]{3}{*}{ A } & & $R^{2}=3 \%$ & & & & $R^{2}=2 \%$ & & \\
\hline & Race & 1.00 & 0.90 & 0.27 & Race & 8.96 & 9.87 & 0.36 \\
\hline & & $R^{2}=13 \%$ & & & & $R^{2}=12 \%$ & & \\
\hline \multirow[t]{3}{*}{ B } & Race & 1.96 & 0.98 & 0.05 & Race & 19.23 & 10.75 & 0.07 \\
\hline & $S_{1}$ & 0.42 & 0.21 & 0.04 & $S_{1}$ & 4.47 & 2.25 & 0.05 \\
\hline & & $R^{2}=3 \%$ & & & & $R^{2}=7 \%$ & & \\
\hline \multirow[t]{3}{*}{ C } & Race & 0.98 & 0.92 & 0.28 & Race & 8.49 & 9.79 & 0.39 \\
\hline & VAT & -0.002 & 0.007 & 0.73 & VAT & -0.09 & 0.07 & 0.22 \\
\hline & & $R^{2}=14 \%$ & & & & $R^{2}=13 \%$ & & \\
\hline \multirow[t]{3}{*}{$\mathrm{D}$} & Race & 2.16 & 1.03 & 0.04 & Race & 18.01 & 11.39 & 0.11 \\
\hline & $S_{1}$ & 0.50 & 0.23 & 0.04 & $S_{1}$ & 4.00 & 2.60 & 0.12 \\
\hline & VAT & 0.005 & 0.007 & 0.50 & VAT & -0.03 & 0.08 & 0.71 \\
\hline
\end{tabular}

${ }^{1}$ Whites are the referent group. 
variables made a significant contribution to apoAI content of HDL without apoCIII (Table 3, Model D).

\section{ApoCIII concentration in HDL and apoB lipoproteins during the test meal}

The apoCIII concentrations of HDL, total apoB lipoproteins, light VLDL, dense VLDL, IDL and LDL during the test meal were not significantly different by race (Figure 2, left panels). However, after controlling for $S_{\mathrm{I}}$, AfricanAmerican women have significantly lower apoCIII level in total apoB lipoproteins, light VLDL and dense VLDL than whites, $P=0.02,0.02$ and 0.01 respectively. (Figure $2 \mathrm{~B}, \mathrm{C}$ and $\mathrm{D}$, right panels). The differences between the groups in apoCIII in total apoB lipoproteins, light VLDL, dense VLDL and IDL increased during the 6-hour postprandial study. There were no significant differences in apoCIII levels in HDL, IDL or LDL by race even after controlling for $\mathrm{S}_{\mathrm{I}}$ (Figure 2A, E and F, right panels).

\section{Determinants of apoCIII levels in HDL and apoB lipoproteins}

The influence of $S_{\text {I }}$ and VAT on the difference between the groups in the apoCIII concentrations in HDL and apoB lipoproteins was studied in multivariable models. Controlling for $\mathrm{S}_{\mathrm{I}}$, African-American women had lower apoCIII in total apoB lipoproteins, light VLDL and dense VLDL than whites (Table 4, model B). $\mathrm{S}_{\mathrm{I}}$ was inversely related to apoCIII level in light VLDL and total apoB lipoproteins. Neither race nor $S_{I}$ was a determinant of apoCIII concentration in HDL, IDL and LDL.

With race and VAT included as independent variables, VAT was a significant determinant of apoCIII concentration in total apoB lipoproteins, light VLDL, dense VLDL, IDL and LDL (all $P \leq 0.04$ ), but did not influence the relation between race and apoCIII (Table 4, model C). Importantly, the overall $\mathrm{R}^{2}$ for total apoB lipoproteins, light VLDL, dense VLDL and IDL model $C$ were higher than for the preceding model in which the two independent variables were race and $S_{I}$ indicating the importance of VAT in determining levels of apoCIII in total and specific apoB lipoproteins. After adding both $\mathrm{S}_{\mathrm{I}}$ and VAT to the same model, VAT appeared to have a dominating influence over $\mathrm{S}_{\mathrm{I}}$ on apoCIII in total apoB lipoproteins, light VLDL, dense VLDL and IDL (Table 4, model D).

\section{Discussion}

We report for the first time that African-American compared to white women have a higher level of apoAI in HDL with apoCIII, an HDL subspecies that is associated with increased risk of CHD [15], after controlling for differences in insulin sensitivity. African-American women also tended to have higher levels of apoAI in HDL without apoCIII, which has a protective association with CHD expected for HDL, although not significantly in the fully adjusted model that adjusted for differences in insulin sensitivity and VAT. The African-American group also tended to have a lower apoCIII level in apoB containing lipoproteins than whites after controlling for insulin sensitivity and VAT. These differences between the groups in apoAI with apoCIII, and in apoCIII in VLDL and IDL increased during the postprandial period, indicating the importance of studying lipoproteins in response to food intake. Since higher levels of HDL without apoCIII and lower levels of apoliprotein CIII predict lower rates of CHD, the results would suggest lower rather than higher prevalence of CHD in AfricanAmerican women, unless the higher level of HDL with apoCIII is somehow a dominating influence. We do not know how these lipoprotein-related risk factors predict CHD in African-American populations.

We found a complex interrelation among insulin sensitivity, VAT, and racial group, as determinants of apoAI lipoprotein concentrations and apoCIII concentrations in VLDL and IDL (Figure 3). Insulin sensitivity, measured directly by IM-FSIGT, was associated with higher apoAI concentration of both HDL subspecies with and without apoCIII. Insulin sensitivity was also associated with lower levels of apoCIII in total apoB lipoproteins and in VLDL. Because African-Americans have less insulin sensitivity, apoAI would be expected to be lower and apoCIII higher than whites, which is not true. In fact, at any level of insulin sensitivity, African-Americans have higher apoAI with apoCIII and lower apoCIII in apoB lipoproteins. Thus, we hypothesize that there must be strong positive metabolic mechanisms in AfricanAmericans to counteract the effect on apoAI with or without apoCIII, and apoCIII in apoB lipoproteins of low insulin sensitivity.

Low mass of visceral adipose tissue in African-Americans is a candidate mechanism. VAT indeed was associated with higher levels of apoCIII in total apoB lipoproteins, VLDL, IDL and LDL. However, VAT was not associated with apoAI in HDL with or without apoCIII. Thus, the low VAT in African-Americans could counterbalance adverse metabolic effects of low insulin sensitivity at least on apoCIII in apoB lipoproteins. VAT does appear to have a dominating influence over $\mathrm{S}_{\mathrm{I}}$ on apoCIII in apoB lipoproteins as shown by models that include both $\mathrm{S}_{\mathrm{I}}$ and VAT. Still, VAT and insulin sensitivity did not explain the full difference between the groups in apoCIII in light and dense VLDL and in apoB lipoproteins and in apoAI with apoCIII.

Insulin regulates apoAI and apoCIII transcription $[27,28]$. In vitro studies showed insulin upregulated apoAI transcription in hepatocytes through an insulin-responsive core element (IRCE). The IRCE contains a Sp1 binding site, and insulin treatment is associated with serine/threonine phosphorylation of Sp1 resulting in increased Sp1 


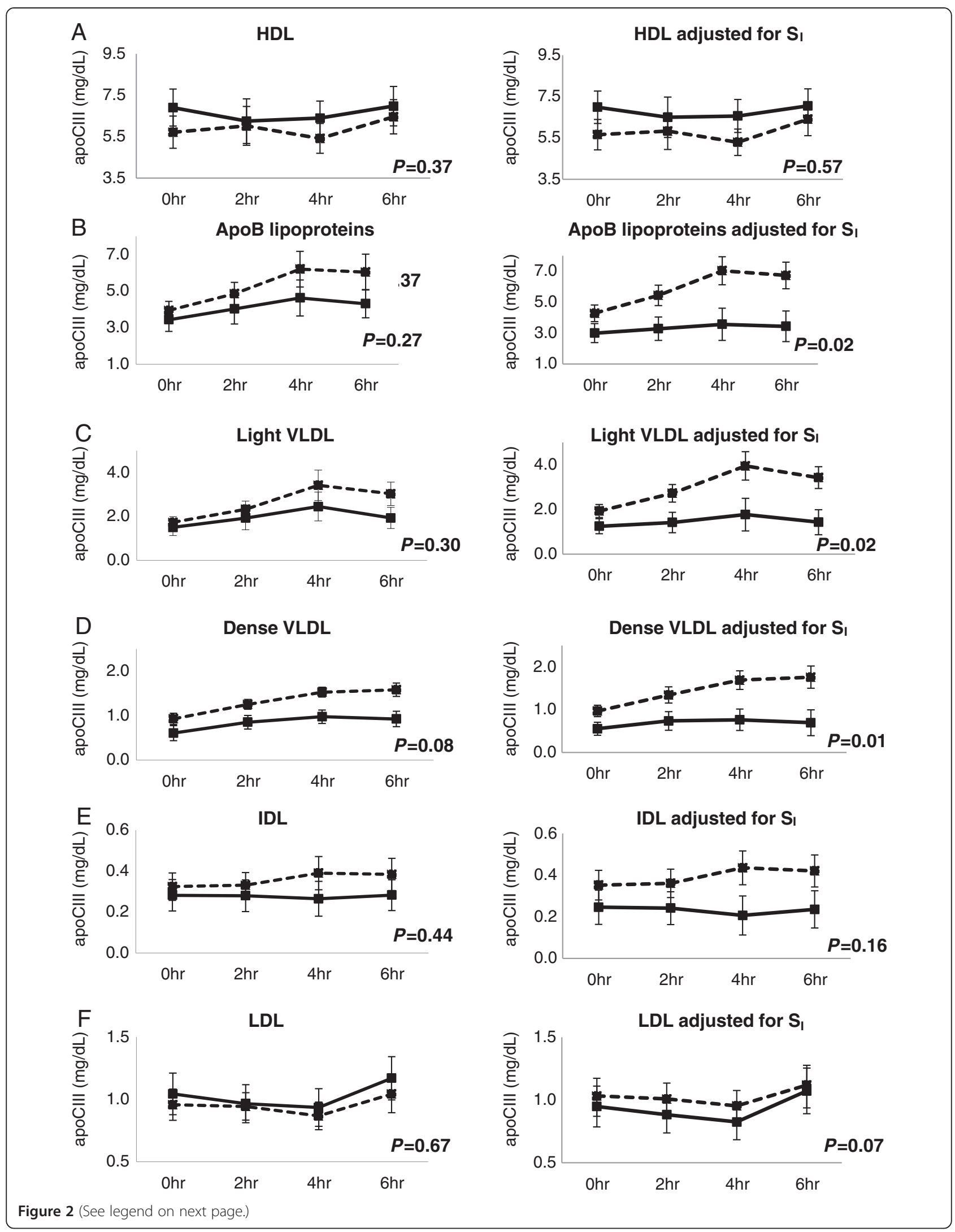


(See figure on previous page.)

Figure 2 ApoCIII concentrations in HDL and apoB lipoproteins at baseline, 2, 4 and 6 hours postprandially. The rows present the apoCIII concentration in HDL (A), total apoB lipoproteins (B), light VLDL (C), dense VLDL (D), IDL (E) and LDL (F). Columns present unadjusted (left panel) and adjusted for $S_{I}$ (right panel). Data are from random effect multiple models constructed to determine the effect of race on the apoCIII concentration in each lipoprotein. The $P$-value for the effect of race is presented in each diagram. African-American women: solid lines; white women: dashed lines.

binding to IRCE $[29,30]$. Altomonte et al. reported that insulin inhibited apoCIII gene expression and synthesis. Forkhead box O1 (Foxo 1), a nuclear transcription factor, is associated with the inhibitory effect of insulin on apoCIII expression [31]. In our study, insulin sensitivity is positively associated with apoAI in HDL with apoCIII or without apoCIII but inversely with apoCIII in apoB lipoproteins. All this evidence suggests that insulin may induce an opposing effect on apoAI level and apoCIII level through the transcriptional regulation of these two apolipoproteins.
In lean individuals with normal insulin sensitivity and people with insulin resistance, African-Americans have significantly lower apoCIII levels than whites $[19,20]$. In states of insulin resistance, an inhibitory role of insulin on apoCIII expression may be lost [32]. Florez et al. reported that the increment in apoCIII level associated with diabetes status and higher degree of insulin resistance was evident in Hispanics and white non-Hispanics but not in African-Americans [20]. Thus, at a similar level of insulin resistance, African-Americans have lower apoCIII than whites.

Table 4 Random effects model to determine influence of race ${ }^{1}, S_{I}$ and VAT on apoCIII level

\begin{tabular}{|c|c|c|c|c|c|c|c|c|c|c|c|c|}
\hline \multirow[b]{2}{*}{ Model } & \multicolumn{4}{|c|}{ ApoCIII - HDL } & \multicolumn{4}{|c|}{ ApoCIII - apoB lipoproteins } & \multicolumn{4}{|c|}{ ApoCIII - Light VLDL } \\
\hline & Variables & $\beta$-coef & SE & $P$-val & Variables & $\beta$-coef & SE & $P$-val & Variables & $\beta$-coef & SE & $P$-val \\
\hline \multirow[t]{3}{*}{ A } & & $R^{2}=2 \%$ & & & & $R^{2}=3 \%$ & & & & $R^{2}=3 \%$ & & \\
\hline & Race & 0.97 & 1.09 & 0.37 & Race & -1.16 & 1.06 & 0.27 & Race & -0.68 & 0.65 & 0.30 \\
\hline & & $R^{2}=3 \%$ & & & & $R^{2}=18 \%$ & & & & $R^{2}=17 \%$ & & \\
\hline \multirow[t]{3}{*}{ B } & Race & 0.73 & 1.27 & 0.57 & Race & -2.55 & 1.11 & 0.02 & Race & -1.54 & 0.68 & 0.02 \\
\hline & $\mathrm{S}_{1}$ & -0.11 & 0.27 & 0.69 & $S_{1}$ & -0.60 & 0.23 & 0.01 & $S_{1}$ & -0.38 & 0.14 & 0.01 \\
\hline & & $R^{2}=2 \%$ & & & & $R^{2}=25 \%$ & & & & $R^{2}=23 \%$ & & \\
\hline \multirow[t]{3}{*}{ C } & Race & 0.98 & 1.11 & 0.38 & Race & -1.04 & 0.91 & 0.25 & Race & -0.60 & 0.56 & 0.28 \\
\hline & VAT & 0.001 & 0.01 & 0.86 & VAT & 0.02 & 0.01 & 0.001 & VAT & 0.01 & 0.004 & 0.001 \\
\hline & & $R^{2}=3 \%$ & & & & $R^{2}=29 \%$ & & & & $R^{2}=27 \%$ & & \\
\hline \multirow[t]{4}{*}{$\mathrm{D}$} & Race & 0.72 & 1.35 & 0.59 & Race & -1.81 & 1.07 & 0.09 & Race & -1.10 & 0.66 & 0.09 \\
\hline & $S_{1}$ & -0.11 & 0.31 & 0.72 & $S_{1}$ & -0.32 & 0.24 & 0.19 & $S_{1}$ & -0.21 & 0.15 & 0.16 \\
\hline & VAT & -0.0001 & 0.01 & 0.99 & VAT & 0.02 & 0.01 & 0.01 & VAT & 0.01 & 0.005 & 0.02 \\
\hline & & \multicolumn{3}{|c|}{ ApoCIII - dense VLDL } & \multicolumn{4}{|c|}{ ApoCIII - IDL } & \multicolumn{4}{|c|}{ ApoCIII - LDL } \\
\hline Model & Variables & $\beta$-coef & SE & $P$-val & Variables & $\beta$-coef & SE & $P$-val & Variables & $\beta$-coef & SE & $P$-val \\
\hline \multirow[t]{3}{*}{ A } & & $R^{2}=7 \%$ & & & & $R^{2}=2 \%$ & & & & $R^{2}=0.5 \%$ & & \\
\hline & Race & -0.48 & 0.27 & 0.08 & Race & -0.08 & 0.10 & 0.44 & Race & 0.08 & 0.18 & 0.67 \\
\hline & & $R^{2}=15 \%$ & & & & $R^{2}=8 \%$ & & & & $R^{2}=8 \%$ & & \\
\hline \multirow[t]{3}{*}{$B$} & Race & -0.75 & 0.3 & 0.01 & Race & -0.16 & 0.12 & 0.17 & Race & -0.10 & 0.20 & 0.63 \\
\hline & $S_{1}$ & -0.12 & 0.06 & 0.06 & $\mathrm{~S}_{1}$ & -0.03 & 0.02 & 0.16 & $\mathrm{~S}_{1}$ & -0.07 & 0.04 & 0.07 \\
\hline & & $R^{2}=21 \%$ & & & & $R^{2}=16 \%$ & & & & $R^{2}=10 \%$ & & \\
\hline \multirow[t]{3}{*}{$C$} & Race & -0.46 & 0.25 & 0.07 & Race & -0.07 & 0.10 & 0.47 & Race & 0.09 & 0.17 & 0.60 \\
\hline & VAT & 0.005 & 0.002 & 0.01 & VAT & 0.002 & 0.001 & 0.02 & VAT & 0.003 & 0.001 & 0.04 \\
\hline & & $R^{2}=23 \%$ & & & & $R^{2}=16 \%$ & & & & $R^{2}=12 \%$ & & \\
\hline \multirow[t]{3}{*}{ D } & Race & -0.59 & 0.3 & 0.05 & Race & -0.10 & 0.12 & 0.40 & Race & -0.02 & 0.20 & 0.93 \\
\hline & $\mathrm{S}_{\mathrm{I}}$ & -0.05 & 0.07 & 0.43 & $S_{1}$ & -0.01 & 0.03 & 0.26 & $S_{1}$ & -0.05 & 0.05 & 0.32 \\
\hline & VAT & 0.004 & 0.002 & 0.05 & VAT & 0.001 & 0.001 & 0.08 & VAT & 0.002 & 0.001 & 0.18 \\
\hline
\end{tabular}




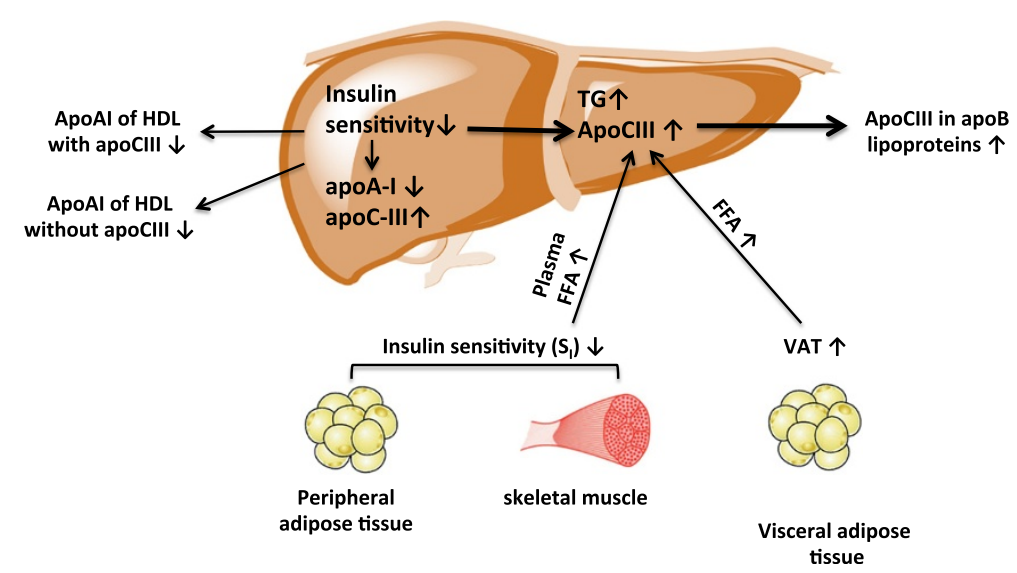

Figure 3 Metabolic pathways suggested by the results of this study. Increased visceral adipose tissue increases flux of FFA to the liver. The liver responds by increasing the secretion of apoC-III in apoB lipoproteins. Lower total body insulin sensitivity including in skeletal muscle and peripheral adipose tissue increases plasma FFA, which increases secretion of apoC-III in apoB lipoproteins. Lower insulin sensitivity reduces apoAl level in HDL with apoCIII, and in HDL without apoCIII. African-American race is associated with increased apoAl of HDL with apoCIII, and decreased apoCIII in apoB lipoproteins, independent of differences in insulin sensitivity and VAT.

Kinetics studies in human subjects have shown that increased production rate of apoCIII rather than decreased apoCIII fractional catabolic rate is a determinant of the elevated plasma apoCIII levels that characterize patients with hypertriglyceridemia and features of insulin resistance [33], consistent with the effect of insulin resistance on the apoCIII promoter. In fact, evidence suggests that African-Americans may have lower apoCIII production rate than whites $[20,33]$. There are several factors that may contribute to the difference of apoCIII production rate in addition to insulin between African-American and whites. In vitro, activation of PPAR alpha is associated with reduced apoCIII gene expression. Shin et al. reported that two minor allele frequencies, L162V and rs4253728 which were associated with the increases in plasma levels of apoCIII, were significantly lower in African Americans compared with whites [19]. Plasma free fatty acids stimulate apoCIII production in humans [34]. Miller et al. reported that obese African-American women with T2DM have lower postabsorptive plasma FFA that whites [35]. All these evidence suggest that genetic variants in the apoCIII promoter region and lower postprandial plasma FFA in African-Americans may induce lower apoCIII level than whites.

\section{Study limitations}

The two major limitations of the study are the lack of kinetics data on lipoproteins to explore mechanisms and our sample size of 32 which may have rendered the study underpowered to detect differences between the groups. The numerous borderline significant $\mathrm{p}$-values may reflect the relatively small sample.

\section{Study strengths}

A major strength of study is how similar the AfricanAmerican and white women were in age, BMI, family history of diabetes and socioeconomic factors. An additional strength is that the women were provided with a diet with the same daily distribution of nutrients for one week prior to the postprandial study. Furthermore, we directly measured $\mathrm{S}_{\mathrm{I}}$ using the Minimal Model.

\section{Conclusion}

African-American women have higher apoAI in HDL with apoCIII and lower apoCIII in apoB lipoprotein postprandially. The differences between the groups in apoAI in HDL with apoCIII, and in apoCIII in VLDL and IDL increased during the postprandial period, indicating the importance of studying lipoproteins in response to food intake. We found a complex interrelation among insulin sensitivity, VAT and racial group, as determinants of apoAI lipoprotein concentrations and apoCIII concentrations in VLDL and IDL. The differences in HDL with apoCIII level and apoCIII in apoB lipoproteins level between races are obscured by lower insulin sensitivity, because insulin sensitivity is associated with higher levels of HDL with apoCIII and lower levels of apoCIII in apoB lipoproteins. In contrast to SI, VAT has a strong association with apoCIII in apoB lipoproteins but not with apoAI with apoCIII level. VAT and insulin sensitivity did not explain the full difference between the groups in apoCIII in light and dense VLDL and in apoB lipoproteins and in apoAI with apoCIII. However, our results suggest that insulin sensitivity and VAT contribute to the differences in lipoprotein levels, which are associated with CHD risk, between African-American women and white women. 


\section{Competing interests}

The authors declare that they have no competing interests.

\section{Authors' contributions}

All authors read and approved the final manuscript.

\section{Acknowledgements}

Anne E. Sumner and Madia Ricks were supported by the intramural program of NIDDK, NIH. Amber B. Courville was supported by the Nutrition Department of the Clinical Center, $\mathrm{NIH}$.

\section{Author details}

${ }^{1}$ Department of Nutrition, Harvard School of Public Health, 665 Huntington Avenue, Building 1, Room 201, Boston, MA 02115, USA. ${ }^{2}$ Channing Division of Network Medicine, Department of Medicine, Brigham and Women's Hospital and Harvard Medical School, Boston, MA, USA. ${ }^{3}$ Diabetes, Endocrinology and Obesity Branch, National Institute of Diabetes, Digestive and Kidney Diseases, National Institutes of Health, Bethesda, MD, USA. ${ }^{4}$ Nutrition Department, Clinical Center, National Institutes of Health, Bethesda, Maryland.

Received: 21 October 2014 Accepted: 5 December 2014 Published: 17 December 2014

\section{References}

1. Park YW, Zhu S, Palaniappan L, Heshka S, Carnethon MR, Heymsfield SB: The metabolic syndrome: prevalence and associated risk factor findings in the US population from the Third National Health and Nutrition Examination Survey, 1988-1994. Arch Intern Med 2003, 163(4):427-436.

2. Jolly S, Vittinghoff E, Chattopadhyay A, Bibbins-Domingo K: Higher cardiovascular disease prevalence and mortality among younger blacks compared to whites. Am J Med 2010, 123(9):811-818.

3. Bachorik PS, Lovejoy KL, Carroll MD, Johnson CL: Apolipoprotein B and AI distributions in the United States, 1988-1991: results of the National Health and Nutrition Examination Survey III (NHANES III). Clin Chem 1997, 43(12):2364-2378.

4. Guerrero R, Vega GL, Grundy SM, Browning JD: Ethnic differences in hepatic steatosis: an insulin resistance paradox? Hepatology (Baltimore, Md) 2009, 49(3):791-801.

5. Sumner $A E$, Cowie $C C$ : Ethnic differences in the ability of triglyceride levels to identify insulin resistance. Atherosclerosis 2008, 196(2):696-703.

6. Chow CC, Periwal V, Csako G, Ricks M, Courville AB, Miller BV 3rd, Vega GL, Sumner AE: Higher acute insulin response to glucose may determine greater free fatty acid clearance in African-American women. J Clin Endocrinol Metab 2011, 96(8):2456-2463.

7. Sumner AE, Micklesfield LK, Ricks M, Tambay AV, Avila NA, Thomas F, Lambert EV, Levitt NS, Evans J, Rotimi CN, Tulloch-Reid MK, Goedecke JH: Waist circumference, BMI, and visceral adipose tissue in white women and women of African descent. Obesity (Silver Spring, Md) 2011, 19(3):671-674.

8. Abbasi F, Brown BW, Lamendola C, McLaughlin T, Reaven GM: Relationship between obesity, insulin resistance, and coronary heart disease risk. J Am Coll Cardiol 2002, 40(5):937-943.

9. Tulloch-Reid MK, Hanson RL, Sebring NG, Reynolds JC, Premkumar A, Genovese DJ, Sumner AE: Both subcutaneous and visceral adipose tissue correlate highly with insulin resistance in African Americans. Obes Res 2004, 12(8):1352-1359.

10. Preis SR, Massaro JM, Robins SJ, Hoffmann U, Vasan RS, Irlbeck T, Meigs JB, Sutherland P, D'Agostino RB Sr, O'Donnell CJ, Fox CS: Abdominal subcutaneous and visceral adipose tissue and insulin resistance in the Framingham heart study. Obesity (Silver Spring, Md) 2010, 18(11):2191-2198.

11. Osei K: Metabolic syndrome in blacks: are the criteria right? Curr Diab Rep 2010, 10(3):199-208.

12. Ukegbu UJ, Castillo DC, Knight MG, Ricks M, Miller BV 3rd, Onumah BM, Sumner AE: Metabolic syndrome does not detect metabolic risk in African men living in the U.S. Diabetes Care 2011, 34(10):2297-2299.

13. Yu SS, Ramsey NL, Castillo DC, Ricks M, Sumner AE: Triglyceride-based screening tests fail to recognize cardiometabolic disease in African immigrant and African-American men. Metab Syndr Relat Disord 2013, $11(1): 15-20$.
14. Mendivil CO, Rimm EB, Furtado J, Chiuve SE, Sacks FM: Low-density lipoproteins containing apolipoprotein C-III and the risk of coronary heart disease. Circulation 2011, 124(19):2065-2072.

15. Jensen MK, Rimm EB, Furtado JD, Sacks FM: Apolipoprotein C-III as a potential modulator of the association between HDL-Cholesterol and incident coronary heart disease. J Am Heart Assoc 2012, 1:e000232.

16. Sacks FM, Alaupovic P, Moye LA, Cole TG, Sussex B, Stampfer MJ, Pfeffer MA, Braunwald $E: V L D L$, apolipoproteins $B, C I I I$, and $E$, and risk of recurrent coronary events in the Cholesterol and Recurrent Events (CARE) Trial. Circulation 2000, 102(16):1886-1892.

17. Chivot L, Mainard F, Bigot E, Bard JM, Auget JL, Madec Y, Fruchart JC: Logistic discriminant analysis of lipids and apolipoproteins in a population of coronary bypass patients and the significance of apolipoproteins C-III and E. Atherosclerosis 1990, 82(3):205-211.

18. Luc G, Fievet C, Arveiler D, Evans AE, Bard JM, Cambien F, Fruchart JC, Ducimetiere P: Apolipoproteins C-III and E in apoB- and non-apoBcontaining lipoproteins in two populations at contrasting risk for myocardial infarction: the ECTIM study. Etude Cas Temoins sur 'Infarctus du Myocarde. J Lipid Res 1996, 37(3):508-517.

19. Shin MJ, Kanaya AM, Krauss RM: Polymorphisms in the peroxisome proliferator activated receptor alpha gene are associated with levels of apolipoprotein CIII and triglyceride in African-Americans but not Caucasians. Atherosclerosis 2008, 198(2):313-319.

20. Florez H, Mendez A, Casanova-Romero P, Larreal-Urdaneta C, Castillo-Florez S, Lee D, Goldberg R: Increased apolipoprotein C-III levels associated with insulin resistance contribute to dyslipidemia in normoglycemic and diabetic subjects from a triethnic population. Atherosclerosis 2006, 188(1):134-141.

21. Sumner AE, Furtado JD, Courville AB, Ricks M, Younger-Coleman N, Tulloch-Reid MK, Sacks FM: ApoC-III and visceral adipose tissue contribute to paradoxically normal triglyceride levels in insulin-resistant African-American women. Nutr Metab 2013, 10(1):73.

22. Bansal S, Buring JE, Rifai N, Mora S, Sacks FM, Ridker PM: Fasting compared with nonfasting triglycerides and risk of cardiovascular events in women. JAMA 2007, 298(3):309-316.

23. Mora S, Rifai N, Buring JE, Ridker PM: Fasting compared with nonfasting lipids and apolipoproteins for predicting incident cardiovascular events. Circulation 2008, 118(10):993-1001.

24. The TG and HDL Working Group of the Exome Sequencing Project, National Heart, Lung, and Blood Institute: Loss-of-function mutations in APOC3, triglycerides, and coronary disease. N Engl J Med 2014, 371(1):22-31.

25. Adiels M, Olofsson SO, Taskinen MR, Boren J: Overproduction of very low-density lipoproteins is the hallmark of the dyslipidemia in the metabolic syndrome. Arterioscler Thromb Vasc Biol 2008, 28(7):1225-1236.

26. Choi SH, Ginsberg HN: Increased very low density lipoprotein (VLDL) secretion, hepatic steatosis, and insulin resistance. Trends Endocrinol Metab 2011, 22(9):353-363.

27. Chen M, Breslow JL, Li W, Leff T: Transcriptional regulation of the apoC-III gene by insulin in diabetic mice: correlation with changes in plasma triglyceride levels. J Lipid Res 1994, 35(11):1918-1924.

28. Dallinga-Thie GM, Groenendijk M, Blom RN, De Bruin TW, De Kant E: Genetic heterogeneity in the apolipoprotein C-III promoter and effects of insulin. J Lipid Res 2001, 42(9):1450-1456.

29. Murao K, Wada Y, Nakamura T, Taylor AH, Mooradian AD, Wong NC: Effects of glucose and insulin on rat apolipoprotein A-I gene expression. J Biol Chem 1998, 273(30):18959-18965.

30. Lam JK, Matsubara S, Mihara K, Zheng XL, Mooradian AD, Wong NC: Insulin induction of apolipoprotein Al, role of Sp1. Biochemistry 2003, 42(9):2680-2690.

31. Altomonte J, Cong L, Harbaran S, Richter A, Xu J, Meseck M, Dong HH: Foxo1 mediates insulin action on apoC-III and triglyceride metabolism. J Clin Invest 2004, 114(10):1493-1503.

32. Caron S, Verrijken A, Mertens I, Samanez CH, Mautino G, Haas JT, Duran-Sandoval D, Prawitt J, Francque S, Vallez E, Muhr-Tailleux A, Berard I, Kuipers F, Kuivenhoven JA, Biddinger SB, Taskinen MR, Van Gaal L, Staels B: Transcriptional activation of apolipoprotein CIII expression by glucose may contribute to diabetic dyslipidemia. Arterioscler Thromb Vasc Biol 2011, 31(3):513-519.

33. Cohn JS, Patterson BW, Uffelman KD, Davignon J, Steiner G: Rate of production of plasma and very-low-density lipoprotein (VLDL) apolipoprotein C-III is strongly related to the concentration and level of production of VLDL 
triglyceride in male subjects with different body weights and levels of insulin sensitivity. J Clin Endocrinol Metab 2004, 89(8):3949-3955.

34. Pavlic M, Valero R, Duez H, Xiao C, Szeto L, Patterson BW, Lewis GF:

Triglyceride-rich lipoprotein-associated apolipoprotein C-III production is stimulated by plasma free fatty acids in humans. Arterioscler Thromb Vasc Biol 2008, 28(9):1660-1665.

35. Miller BV 3rd, Patterson BW, Okunade A, Klein S: Fatty acid and very low density lipoprotein metabolism in obese African American and Caucasian women with type 2 diabetes. J Lipid Res 2012,

53(12):2767-2772

doi:10.1186/1743-7075-11-56

Cite this article as: Wang et al:: Racial differences between African-

American and white women in insulin resistance and visceral adiposity are associated with differences in apoCIII containing apoAl and apoB

lipoproteins. Nutrition \& Metabolism 2014 11:56.

\section{Submit your next manuscript to BioMed Central and take full advantage of:}

- Convenient online submission

- Thorough peer review

- No space constraints or color figure charges

- Immediate publication on acceptance

- Inclusion in PubMed, CAS, Scopus and Google Scholar

- Research which is freely available for redistribution 